\title{
Subgroups of Long-Term Sick-Listed Based on Prognostic Return to Work Factors Across Diagnoses: A Cross-Sectional Latent Class Analysis
}

\author{
Martin Inge Standal ${ }^{1}$ (i) $\cdot$ Lene Aasdahl ${ }^{2,3} \cdot$ Chris Jensen $^{2,4} \cdot$ Vegard Stolsmo Foldal $^{2} \cdot$ Roger Hagen $^{1}$. \\ Egil Andreas Fors ${ }^{5} \cdot$ Marit Solbjør $^{2} \cdot$ Odin Hjemdal $^{1} \cdot$ Margreth Grotle $^{6,7} \cdot$ Ingebrigt Meisingset ${ }^{2}$
}

Accepted: 29 September 2020 / Published online: 14 October 2020

(C) The Author(s) 2020

\begin{abstract}
Comorbidity is common among long-term sick-listed and many prognostic factors for return to work (RTW) are shared across diagnoses. RTW interventions have small effects, possibly due to being averaged across heterogeneous samples. Identifying subgroups based on prognostic RTW factors independent of diagnoses might help stratify interventions. The aim of this study was to identify and describe subgroups of long-term sick-listed workers, independent of diagnoses, based on prognostic factors for RTW. Latent class analysis of 532 workers sick-listed for eight weeks was used to identify subgroups based on seven prognostic RTW factors (self-reported health, anxiety and depressive symptoms, pain, self-efficacy, work ability, RTW expectations) and four covariates (age, gender, education, physical work). Four classes were identified: Class 1 (45\% of participants) was characterized by favorable scores on the prognostic factors; Class 2 (22\%) by high anxiety and depressive symptoms, younger age and higher education; Class 3 (16\%) by overall poor scores including high pain levels; Class 4 (17\%) by physical work and lack of workplace adjustments. Class 2 included more individuals with a psychological diagnosis, while diagnoses were distributed more proportionate to the sample in the other classes. The identified classes illustrate common subgroups of RTW prognosis among long-term sick-listed individuals largely independent of diagnosis. These classes could in the future assist RTW services to provide appropriate type and extent of follow-up, however more research is needed to validate the class structure and examine how these classes predict outcomes and respond to interventions.
\end{abstract}

Keywords Sick leave $\cdot$ Return to work $\cdot$ Vocational rehabilitation $\cdot$ Common mental disorder $\cdot$ Pain

Martin Inge Standal

martin.standal@ntnu.no

1 Department of Psychology, Faculty of Social and Educational Sciences, Norwegian University of Science and Technology, Trondheim, Norway

2 Department of Public Health and Nursing, Faculty of Medicine and Health Sciences, Norwegian University of Science and Technology, Trondheim, Norway

3 Unicare Helsefort Rehabilitation Centre, Rissa, Norway

4 National Center for Occupational Rehabilitation, Rauland, Norway

5 General Practice Research Unit, Department of Public Health and Nursing, Faculty of Medicine and Health Sciences, Norwegian University of Science and Technology, Trondheim, Norway

6 Department of Physiotherapy, Faculty of Health Sciences, Oslo Metropolitan University, Oslo, Norway

7 Department for Research of Musculoskeletal Disorders (FORMI), Oslo University Hospital, Oslo, Norway

\section{Background}

Prolonged sickness absence is costly for society and associated with adverse health outcomes and comorbidity for the individual [1]. In order to help individuals return to work (RTW) effective vocational rehabilitation interventions are required as healthcare treatment alone has little impact on work outcomes [2]. However, the results of such interventions are inconclusive [3-6]. The variation in effectiveness found in RTW interventions could partly be due to the effects being averaged across heterogeneous samples, meaning some subgroups will have no benefit or possibly even experience negative outcomes of these interventions [7]. Diagnosis is also often used as basis for recruitment into such interventions, even though diagnosis provides limited information of the complexity and interrelationship between factors associated with prognosis $[8,9]$. For example, musculoskeletal and psychological 
disorders, the most prevalent diagnoses for loss of work days in Norway [10] and major causes of disability worldwide [11], have considerable comorbidity and several shared prognostic factors for RTW [12-16]. In addition, patterns of relapse between RTW and sick leave are common for both of these diagnostic categories [17, 18]. An alternative approach could be using known factors that influence RTW for early identification of subgroups at risk of prolonged sick leave, regardless of diagnosis.

Identifying subgroups that can be used to stratify care is challenging and has been a focus of research in some fields for many years [19], mainly in patients with musculoskeletal disorders [20-23]. Such stratification approaches have shown effective in treatment of patients with low back pain [24]. However, few studies have attempted to identify subgroups based on prognostic RTW factors independent of diagnoses. One recent study identified subgroups of unemployed sick-listed individuals based on their predicted risk of long-term sickness absence and found four groups characterized by negative RTW expectations, positive RTW expectations, mental limitations and physical limitations [25]. Such research is still lacking for those with an employment contract. As many social insurance and healthcare professionals serve varied user groups, identifying homogeneous subgroups independent of diagnosis could assist these services to channel resources towards those who may benefit the most [26].

The aim of the present study was to identify and describe subgroups of long-term sick-listed workers, independent of diagnoses, based on prognostic factors for RTW. In particular, we wanted to investigate the following research questions:

1. What characterizes subgroups of long-term sick listed workers, independent of diagnoses, based on prognostic factors?

2. How are the psychological and musculoskeletal diagnostic categories distributed within these subgroups?

\section{Methods}

\section{Study Design}

This cross-sectional study used data from a cohort of sick-listed workers in an ongoing randomized controlled trial [27]. All data in the present study were collected at inclusion in the trial, prior to randomization. The study was approved by the Regional Committee for Medical and Health Research Ethics in South East Norway (No: 2016/2300). Written informed consent was obtained from all participants.

\section{Study Setting}

In Norway, employees are entitled to 12 months of full wage benefits when on sick leave. For the first 16 days of sick leave wages are paid by the employer, while the remaining year is paid for by the National Insurance Scheme through the Norwegian Labour and Welfare Administration (NAV) [28].

\section{Participants and Recruitment}

Participants in the present study were employed workers aged 18-62 on sick leave for eight weeks the previous 6 months, with a current sick leave status of $50-100 \%$. Eligible participants living in Trondheim, Central Norway, were invited via NAV's electronic communication site. Data from participants included in the trial from August 2017 to October 2019 were used in the present study. In this period 4708 individuals were invited, of which 709 (15\%) accepted and received a questionnaire by e-mail at eight weeks of sick leave. This questionnaire was answered by $571(81 \%)$ of the included participants.

\section{Measurement Instruments}

The questionnaire included questions related to sociodemographic characteristics, symptoms and health, and workrelated factors. Variables were selected a priori based on a literature search of reviews on prognostic factors for RTW. Factors such as perceived health [29], symptom severity [13], and the possibility of workplace adjustments are predictors for prolonged sick leave [30, 31]. Furthermore, factors such as RTW self-efficacy [15], perceived work ability and RTW expectations have also been shown to be important for RTW [13, 32]. Common sociodemographic factors are age, education, gender, and the physical demands of one's work [13, 16, 32]. In addition, information on participants' current diagnosis was obtained from NAV.

\section{Sociodemographic Characteristics}

Sociodemographic factors included age, gender, educational level and the physical demands of the participants' work. Age was scored as a continuous variable. Education was dichotomized as higher (completed minimum 3 years of college/university) or lower. Participants were asked how physically demanding their job was by describing their work using the categories "Mostly sedentary work", "Work that demand that you walk a lot", "Work where you walk and lift a lot", "Heavy manual labour", and "Do not know / unsure". This variable was dichotomized (physically demanding work 
or not) by combining the two less demanding categories and the two more demanding categories. "Do not know / unsure" was set to missing $(n=18)$.

\section{Symptoms and Health}

Anxiety was assessed using the Generalized Anxiety Disorder-7 questionnaire [33], and depression with the Patient Health Questionnaire-9 [34]. Anxiety and depression scores were combined into the Patient Health Questionnaire Anxiety and Depression Scale (PHQ-ADS), which has shown to be a valid and reliable composite measure of depression and anxiety [35]. The PHQ-ADS was used to assess anxiety and depression symptoms on a scale from 0 to 48 , where 0 indicate low levels of symptoms and 48 indicate high levels of symptoms.

Pain intensity was assessed by an item from the Brief Pain Inventory [36, 37] querying participants to "Describe your average pain intensity the last week" on a scale from 0 (no pain at all) to 10 (worst possible pain).

To detect individuals who may have had other health issues besides anxiety, depression or pain, we included the EQ-VAS analog scale from the EQ-5D-5L questionnaire [38]. This question asks participants to rate their current health on a scale from 0 to 100 ( 0 being worst possible health and 100 being best possible health) and was used to assess general health status.

\section{Work Related Factors}

Workplace adjustment latitude was examined with the question "To what degree do you feel your workplace facilitates work adjustments?". Response options ranged from 1 (to a very low degree) to 10 (to a very high degree).

Self-reported work ability was measured using the work ability score (WAS), which is an item from the Work Ability Index [39]. WAS asks participants about their "current work ability compared with lifetime best" on a scale from 0 (completely unable to work) to 10 (work ability at its best). WAS has been shown to be a good alternative to using the full index [40, 41].

Work related self-efficacy was measured using an 11-item RTW-SE scale [42]. The scale has 11 questions on expectations of working if the participants were to imagine being back to work tomorrow. The scale ranges from 0 "totally disagree to 5 "totally agree". An average score of the 11 items was used.

Return-to-work expectations was measured by the question "Starting today, how many months do you believe you will be sick-listed?". Answers greater than 12 months $(n=14)$ were set to 12 months, as individuals need to apply for more long-term benefits after 12 months [43].

\section{Diagnosis}

Diagnosis was retrieved from the sick leave certificate and obtained from NAV. Diagnosis is usually set by the individual's general practitioner, using the International Classification of Primary Care (ICPC-2) [44]. Diagnoses were categorized as "Musculoskeletal" (ICPC-2 L), "Psychological" (ICPC-2 P), or "Other" (containing all other diagnoses).

\section{Statistical Analysis}

Latent class analysis (LCA) was used to identify classes of sick-listed individuals based on their scoring on the prognostic RTW factors. LCA attempts to identify subgroups, or classes, of individuals who share common characteristics and are as distinct as possible from the other identified subgroups [45]. LCA is a cluster analysis method that has some advantages over traditional techniques. For example, LCA can produce statistical information about model fit that can help guide model selection [46]. The method is also flexible and can be used with different types of data, allows for different subgroup distributions (i.e., shape, size, and orientation), and handles missing values well [46, 47].

The seven a priori chosen prognostic factors included as indicators in the LCA model were anxiety and depression, pain, general health, work ability, workplace adjustment latitude, return to work self-efficacy, and return to work expectations. The sociodemographic variables age, gender, educational level and physically demanding work were included as active covariates in the model (see Fig. 1).

The LCA was performed using an iterative approach starting with a model with a one-class solution and continuing up to seven classes. Model fit was assessed using the adjusted Bayesian Information Criteria (aBIC) [48] as it has been shown to be the most accurate information criteria in simulation [49]. The optimal number of classes was decided based on a combination of aBIC and substantive interpretation (i.e. if the classes are distinct and have practical meaning based on the scoring on the prognostic factors). Based on the scoring patterns, the LCA estimated posterior probabilities for inclusion into each class for each individual, and the participants were assigned to the class where they had the highest posterior probability. A posterior probability above 0.7 is recommended, and 0.9 is suggested as good when assessing uncertainty of the class assignment [50].

We tested several model specifications as suggested by Masyn [51]. First, by allowing (or not allowing) class variances to be unequal across the latent classes. Secondly by relaxing the assumption of local independence by allowing (or not allowing) indicator variables to covary within a class. For the most unrestricted model we then examined the covariance matrices for the indicator residuals in each class and identified pairs of variables whose residuals were 
Latent class model

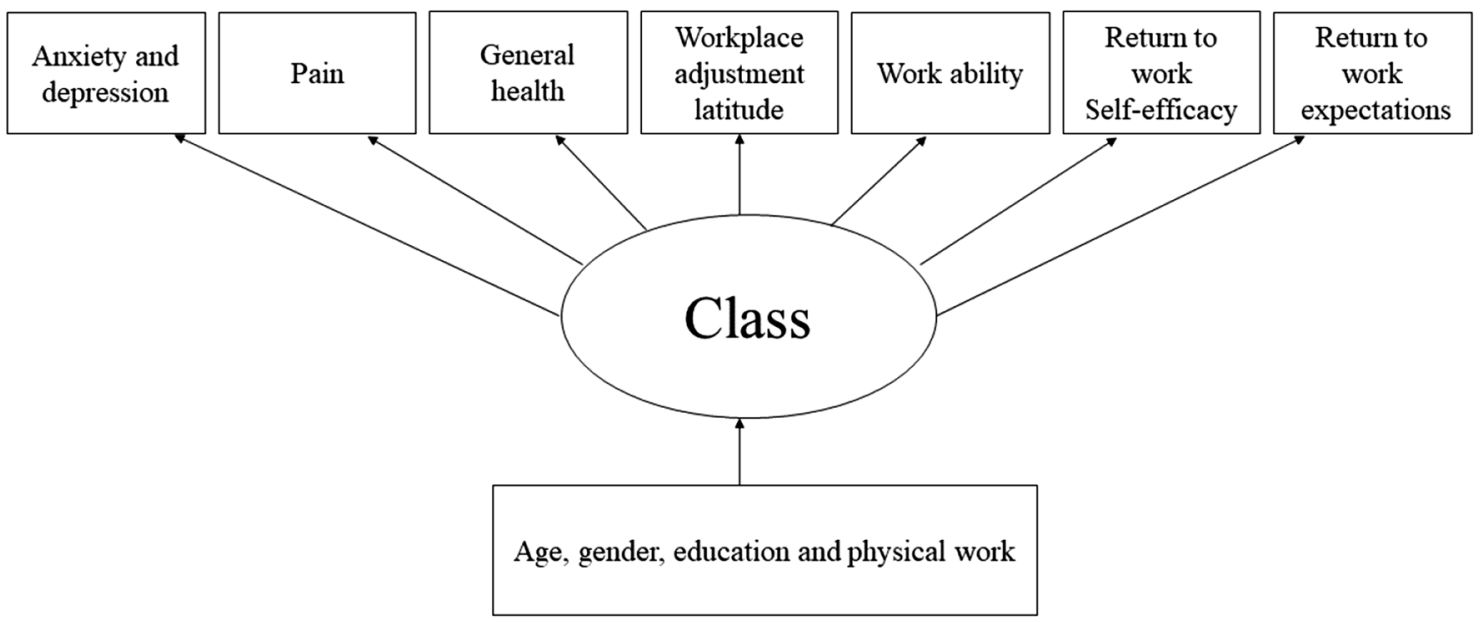

Fig. 1 Latent class model. Indicator variables (anxiety and depression, pain, health, workplace adjustment latitude, work ability, return to work self-efficacy, and return to work expectations) and covariates (age, gender, education and physically demanding work)

significantly associated within a class $(p<0.05)$, indicating local dependence [52]. We then relaxed the assumption of local independence only where local dependence was indicated. For each model, a minimum of 200 random draws were performed in order to achieve an optimal model. After latent class modelling had been performed, we also examined the prevalence of the diagnosis categories within each class.

All analyses were performed using Stata 15.1 (StataCorp. 2017. Stata Statistical Software: Release 15. College Station, TX: StataCorp LLC).

\section{Results}

\section{Sample Description}

The final sample $(n=532)$ consisted of $65 \%$ women, $65 \%$ had higher education and the mean age was 44 years (SD 9.8). The mean symptom scores indicated mild anxiety and depressive symptoms (15.8 SD 10.2) [35], and mild to moderate pain intensity (4.3 SD 2.7) [53]. The mean work ability of 3.5 (SD 2.7) can be described as "poor" [41]. Diagnoses were split by about a third for musculoskeletal (37\%), psychological (32\%), and all other diagnoses (31\%). See Table 2 and Fig. 3 for additional characteristics.

\section{Model Selection}

The more unrestricted models generally had better model fit compared to the more restrictive models (see Table 1). The chosen model specification which presented the best
Table 1 Model fit (adjusted Bayesian Information Criteria) for the latent class models

\begin{tabular}{llllll}
\hline Classes & Model 1 & Model 2 & Model 3 & Model 4 & Model 5 \\
\hline 1 & 19,920 & 19,920 & 19,382 & 19,382 & 19,376 \\
2 & 19,536 & 19,360 & 19,285 & 19,075 & 19,039 \\
3 & 19,419 & 19,187 & 19,042 & 19,023 & 18,994 \\
4 & 19,200 & 19,090 & 19,011 & 18,974 & 18,917 \\
5 & 19,144 & 18,988 & 19,002 & 18,951 & 18,898 \\
6 & 19,122 & 18,950 & 19,009 & 18,959 & 18,908 \\
7 & 19,093 & 18,937 & N/A* & 19,010 & 18,911 \\
\hline
\end{tabular}

Lower fit indices indicate a better-fitting model. Model 1: Classinvariant variances, diagonal covariances between indicator variables within classes. Model 2: Class-varying variances, diagonal indicator covariances. Model 3: Class-invariant variances, unrestricted indicator covariances (*The 7-class model failed to reliably converge). Model 4: Class-varying variances, unrestricted indicator covariances. Model 5: Class-varying variances, unrestricted indicator covariances where local dependence was indicated.

fit included class-varying variances, as well as relaxation of the assumption of local independence for those variables that were found to covary within a class (Model 5 in Table 1). The five-class model presented the lowest aBIC and this model and those with \pm one class were further examined. The four and the five class models showed similar patterns, however the four-class solution was selected based on the interpretation of practical meaning and simplicity. Posterior probabilities were generated for 532 participants, meaning 39 participants had too many missing values to be classified. The average posterior probabilities of class membership in the final model were $0.90,0.83$, 
Table 2 Characteristics of the overall sample and classes (values given are mean (SD), unless otherwise stated)

\begin{tabular}{|c|c|c|c|c|c|}
\hline Variable (full range) & $\begin{array}{l}\text { Sample } \\
n=532\end{array}$ & $\begin{array}{l}\text { Class } 1 \\
n=240 \\
(45 \%)\end{array}$ & $\begin{array}{l}\text { Class } 2 \\
n=114 \\
(22 \%)\end{array}$ & $\begin{array}{l}\text { Class } 3 \\
n=87 \\
(16 \%)\end{array}$ & $\begin{array}{l}\text { Class } 4 \\
n=91 \\
(17 \%)\end{array}$ \\
\hline Age (18-62 years) & $44(10)$ & $46(9)$ & $39(9)$ & $45(10)$ & $45(10)$ \\
\hline Gender (female) $-n(\%)$ & $351(66 \%)$ & $160(67 \%)$ & $81(71 \%)$ & $56(64 \%)$ & $54(59 \%)$ \\
\hline Education (higher) $-n(\%)$ & $351(66 \%)$ & $175(73 \%)$ & $98(86 \%)$ & $31(36 \%)$ & $47(52 \%)$ \\
\hline Physically demanding work (more) $-n(\%)$ & $179(34 \%)$ & $67(28 \%)$ & $13(11 \%)$ & $49(56 \%)$ & $50(55 \%)$ \\
\hline Self-reported health $(0-100)$ & $50.4(20.5)$ & $54.3(20.9)$ & $45.0(18.1)$ & $48.8(23.3)$ & $49.1(18.0)$ \\
\hline Pain intensity $(0-10)$ & $4.3(2.7)$ & $4.1(2.6)$ & $3.1(2.6)$ & $6.1(2.1)$ & $4.2(2.5)$ \\
\hline Anxiety and depressive symptoms $(0-48)$ & $15.8(10.1)$ & $9.1(5.0)$ & $23.8(7.7)$ & $20.7(10.9)$ & $18.5(10.7)$ \\
\hline Work ability $(0-10)$ & $3.5(2.6)$ & $4.1(2.9)$ & $3.4(2.1)$ & $2.4(2.3)$ & $3.4(2.6)$ \\
\hline Workplace adjustment latitude (1-10) & $6.0(3.0)$ & $7.6(2.0)$ & $6.0(2.2)$ & $5.8(3.0)$ & $1.7(0.7)$ \\
\hline Return to work self-efficacy $(0-5)$ & $2.5(1.1)$ & $2.9(1.0)$ & $1.8(0.7)$ & $2.6(1.1)$ & $2.3(1.1)$ \\
\hline Expected sickness absence length ( $0-12$ months) & $3.0(2.7)$ & $1.8(1.2)$ & $3.0(0.7)$ & $6.9(3.7)$ & $2.2(1.6)$ \\
\hline
\end{tabular}

Education: Percentage of individuals that have completed a minimum of 3 years of higher education at the college or university level. Physically demanding work: Percentage of individuals that rate their work as "demanding a lot of walking and lifting" or "heavy manual labour". Selfreported health: Higher number indicate better health. Pain intensity: Higher number indicate more pain. Anxiety and depressive symptoms: Higher number indicate more symptoms. Workplace adjustment latitude: Higher number indicate greater possibility for work adjustment. Return to work self-efficacy: Higher number indicate greater self-efficacy

0.90 and 0.88 in Classes $1-4$ respectively which indicated that subjects were classified with low uncertainty.

\section{Class Prevalence and Characterization}

Table 2 describes the characteristics of the four classes and normalized class profiles can be found in Fig. 2. The first and largest class $(45 \%, n=240)$ was indicative of individuals who had low symptom scores, high RTW self-efficacy and high work ability. Class 2 included $22 \%(n=114)$ of participants and had the highest level of anxiety and depression symptoms, poorest self-efficacy as well as younger age, less physically demanding work and higher education. The third class included $16 \%(n=87)$ of participants and consisted of those with poor scores on several of the prognostic variables, including higher levels of pain, and anxiety and depressive symptoms. They also more frequently had lower education and physically demanding work. Further, individuals in Class 3 expected to be sick listed longer than the other classes. Class 4 included 17\% $(n=91)$ of the participants and was characterized by moderately high pain and anxiety and depressive symptoms. Similar to Class 3 , subjects in Class
Fig. 2 Normalized class profiles. Variables are normalized on a scale from 0 to 1 , where 1 indicates poorer scores. In this representation, mean scores were divided by the variable's full range and reversed where higher numbers originally indicated favorable scores

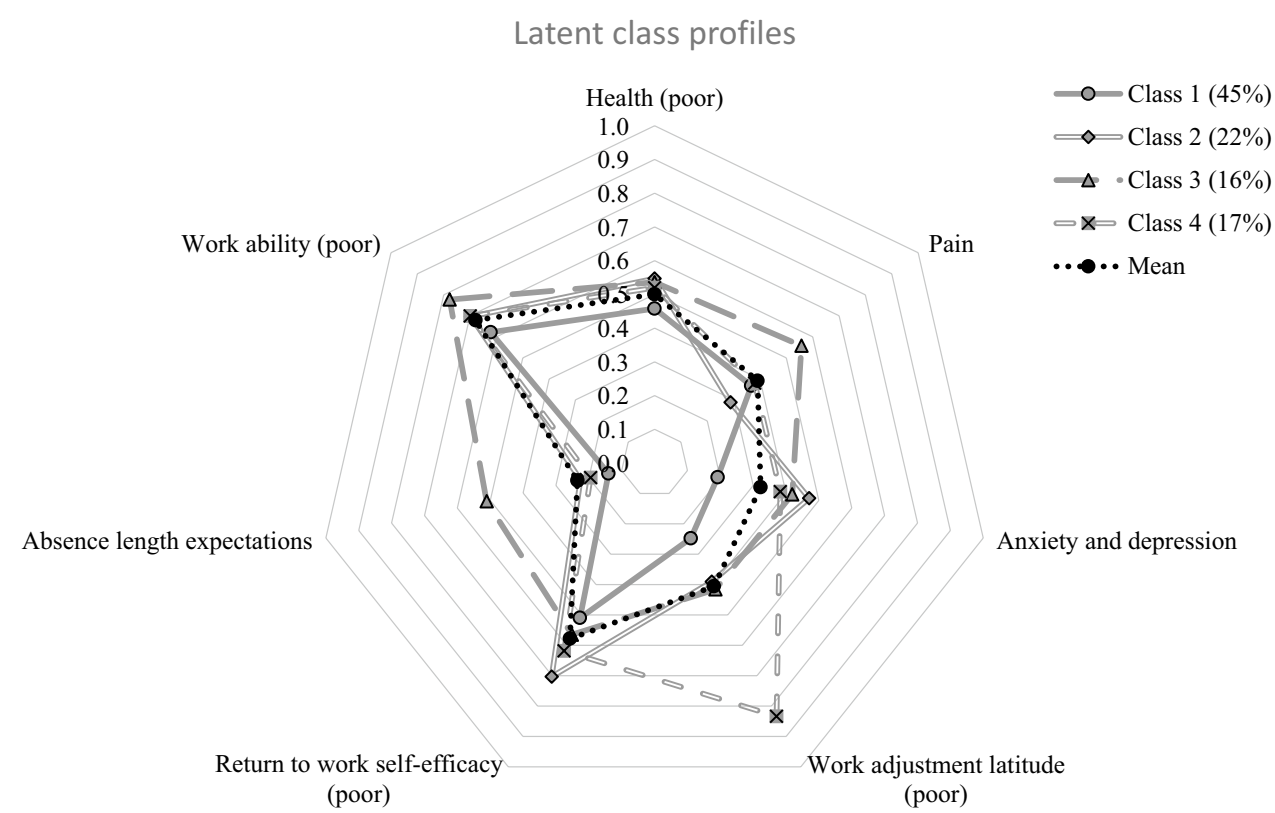


4 more frequently had a physically demanding job than the sample mean, but Class 4 was also characterized by poor possibilities for workplace adjustments.

\section{Diagnosis}

Figure 3 describes the distribution of the diagnosis categories in the sample and classes. Participants with a psychological diagnosis was to a greater degree grouped into Class 2 (62\%). Those with musculoskeletal diagnoses were more evenly distributed between Class 1 (40\%), Class $3(49 \%)$ and Class 4 (50\%). Similarly, "Other" diagnoses were less frequently placed in Class 4 (15\%), but more evenly distributed among the other classes. Diagnosis was missing for 30 participants in the final model.

\section{Discussion}

This cross-sectional study identified four classes of sicklisted individuals based on seven prognostic RTW factors and four covariates. The four classes were characterized by distinct patterns across prognostic RTW factors, largely independent of sick leave diagnosis.

Previous research has attempted to define more homogeneous patient subgroups with the goal of reducing complexity and simplifying treatment options [54]. These endeavors have frequently been based on individual characteristics such as symptoms, pain sites, or other prognostic factors, and usually within defined patient groups. Previous studies have found subgroups that differ in severity [55-57], or subgroups that are qualitatively distinct, for example in symptoms or personal factors [22, 58-60]. For instance, studies using prognostic factors have found subgroups characterized by low risk, mental health issues, physical limitations and pain, and workplace related concerns in patients with musculoskeletal disorders $[61,62]$. The present study adds to the previous literature by grouping individuals regardless of sick leave diagnosis into comparable subgroups that differ both in severity (i.e. most favorable scores on RTW predictors in Class 1, medium in Class 2 and Class 4, and poorest scores in Class 3 ) and qualitatively (e.g. mental health issues and workplace factors in Classes 2 and 4, respectively). The findings suggest that sick-listed individuals can be classified based on prognostic factors rather than diagnosis in an RTW context. A cross-disease approach in the RTW process has also previously been advocated [13].

\section{Implications for Practice}

Identification of those at risk (or not at risk) for prolonged sick leave is important for both social insurance and vocational rehabilitation services in order to create plans for RTW [63]. This is important in order to design rehabilitation services and to allocate appropriate resources based on the expected prevalence of a risk group. Screening to identify and provide additional care to high risk groups with musculoskeletal disorders has shown to reduce time off work for these groups [24].

Class 1, with almost half of the participants, was characterized by advantageous scores on several of the prognostic RTW factors compared to the other classes. Identifying those with good prognosis may be useful in order to avoid excessive assistance (overtreatment) for these individuals [64], which may even delay RTW [65]. However, further research is needed to determine whether individuals in Class 1 have a favorable RTW prognosis.
Fig. 3 Distribution of diagnostic groups based on ICPC-2 diagnoses set by the worker's general practitioner. Percentages within each class and in the total sample

\section{ICPC-2 diagnosis distribution per class (\%)}

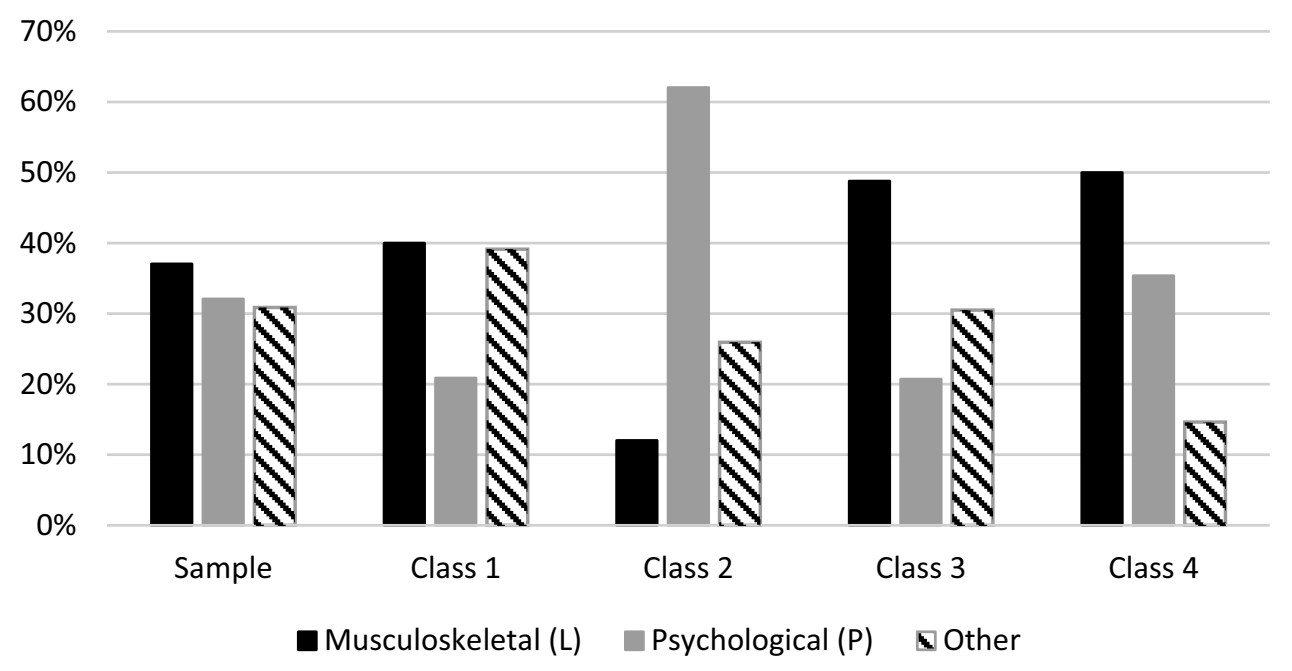


Class 2 was characterized by younger age, anxiety and depressive symptoms, and poor RTW self-efficacy. Furthermore, Class 2 had a higher prevalence of individuals with a psychological diagnosis compared to the other classes. These characteristics indicate that work-focused cognitive therapies that could help promote self-efficacy could be useful for such a group [66, 67]. However, the mean scores for anxiety and depressive symptoms were similar in Class 3 and Class 4 . This indicate that anxiety and depression symptoms were common for those with poorer prognostic scores (Classes 2-4) in the present study regardless of the prevalence of psychological diagnoses in the classes.

Class 3 was characterized by individuals who generally scored poorly on many of the prognostic RTW factors. Individuals in this class reported both pain and mental health symptoms, but more often had a musculoskeletal diagnosis than a psychological diagnosis. For those experiencing chronic pain, research has emphasized that psychosocial factors, such as fear-avoidance beliefs and psychological distress, are associated with poor outcomes [68]. Such factors are common in the first few months after injury [69] but may not always be identified when seeking help for physical symptoms [70]. Previous cluster analyses of musculoskeletal patients have also identified psychologically distressed subgroups [22, 60, 62,71], which could be similar to Class 3 in the present study. Such groups may benefit from broader interventions also focusing on coping, problem solving, and other psychosocial factors $[4,72,73]$.

Class 4 was characterized by physically demanding work in combination with poor possibilities of workplace adjustments. Although some work tasks are difficult to accommodate to individual employees, Class 4 may still indicate a proportion of sick-listed workers where workplace interventions could be sought in order to facilitate RTW as work adjustments are important for RTW [16, 31]. Where adjustments are difficult, interventions could address other aspects of the workplace, such as supervisor support, disability management practices, and workplace culture [71,73]. Some of those experiencing low adjustment latitude after illness may also need help or encouragement in finding a more suitable job. Job changes can be a solution to ill health in order to avoid movement out of employment [74].

In patients with back pain, using risk factors to identify subgroups led to the development of the PRICE tool [61, $62,71,75]$. The PRICE tool can be used to identify those with poor prognosis for RTW and also indicates where assistance should be focused (e.g., the workplace, psychological coping, physical activation) for this patient population [75]. The present study indicated similar subgroups independent of diagnoses as those described in the aforementioned studies, which supports the relevance of our subgrouping approach. The identified subgroups may indicate typical barriers to RTW at this stage of sick leave. Such groups could be used, for instance by social insurance workers who serve a diagnostically varied user group, as a starting point to identify problem areas that could be the focus for vocational rehabilitation interventions. For the present findings, however, further research is needed to examine the practical relevance of prognostic subgrouping across diagnoses. Identification of subgroups based on risk of prolonged sick leave may be useful in itself if the predictive validity of the classes is acceptable. However, it does not necessarily follow that such subgroups respond to interventions. Matching interventions to prognostic risk factors can be difficult and has previously been found to be lacking in practice [73]. Furthermore, investigations of intervention effects for such subgroups require separate carefully designed studies [76].

\section{Strengths and Limitations}

Use of LCA reduced complexity of the variable combinations into four distinct groups and allowed us to identify differences between the classes of long-term sick-listed individuals across diagnoses. Further, using prognostic factors on their continuous scale in the LCA retained all information on the variables, which is useful as sick individuals usually differ on a continuum rather than by dichotomous symptom or diseases states [9]. The classes in the present study were based on a priori identified prognostic factors that are predictors for RTW, thereby increasing theoretical validity.

There are some limitations to drawing strong conclusions from this study. First, the findings in the present study needs to be replicated and the classes validated in representative samples. Additional research should also be performed with additional or different prognostic variables to examine if the class structures and prevalences are significantly altered. Second, sick leave outcomes for these classes should be investigated to examine whether the classes predict prolonged sickness absence. Finally, the study may suffer from selection bias of participants that may affect the composition and prevalence of the classes.

\section{Conclusions}

The present study show that a heterogeneous sample of longterm sick-listed individuals can be classified into four distinct classes based on prognostic RTW factors, largely independent of medical diagnosis. These four classes differed both in severity and qualitatively across prognostic factors for RTW. Identifying subgroups based on prognostic variables might be useful to identify problem areas that could be the focus for additional RTW follow-up. Further research is needed to validate the class structure, the predictive validity of the classes and how they respond to interventions. 
Acknowledgements We particularly thank those who participated in this study. The Norwegian Labour and Welfare Administration provided invaluable help with recruitment.

Author Contributions Conceptualization was performed by Martin Inge Standal, Margreth Grotle, Ingebrigt Meisingset and Roger Hagen; Data material preparation by Egil A. Fors, Roger Hagen, Lene Aasdahl, Marit Solbjør, Odin Hjemdal, Martin Inge Standal and Vegard Stolsmo Foldal; Data collection by Egil A. Fors, Roger Hagen, Lene Aasdahl, Marit Solbjør, Vegard Stolsmo Foldal and Martin Inge Standal; Variable selection by all authors; Latent class analysis by Martin Inge Standal and Ingebrigt Meisingset; Substantive interpretation of classes by all authors. First draft by Martin Inge Standal; Draft revision by all authors. All authors read and approved of the final manuscript.

Funding Open Access funding provided by NTNU Norwegian University of Science and Technology (incl St. Olavs Hospital - Trondheim University Hospital). The Research Council of Norway (Project Number: 256633). Ingebrigt Meisingset received funding from the Norwegian Fund for Post-Graduate training in physiotherapy through the FYSIOPRIM research programme. The funding bodies had no role in the design, data collection, analysis or writing of the manuscript.

Data Availability The datasets generated and analysed during the current study are not publicly available due to protecting the anonymity of participants.

\section{Compliance with Ethical Standards}

Conflict of interest Authors Martin Inge Standal, Lene Aasdahl, Chris Jensen, Vegard Stolsmo Foldal, Roger Hagen, Egil A. Fors, Marit Solbjør, Odin Hjemdal, Margreth Grotle, and Ingebrigt Meisingset declare that they have no conflict of interest.

Ethical Approval The study was approved by the Regional Committee for Medical and Health Research Ethics in South East Norway (No: 2016/2300). All procedures followed were in accordance with the ethical standards of the responsible committee on human experimentation (institutional and national) and with the Helsinki Declaration of 1975, and later revisions.

Informed Consent Informed consent was obtained from all patients for being included in the study. Written informed consent was obtained from all participants.

Open Access This article is licensed under a Creative Commons Attribution 4.0 International License, which permits use, sharing, adaptation, distribution and reproduction in any medium or format, as long as you give appropriate credit to the original author(s) and the source, provide a link to the Creative Commons licence, and indicate if changes were made. The images or other third party material in this article are included in the article's Creative Commons licence, unless indicated otherwise in a credit line to the material. If material is not included in the article's Creative Commons licence and your intended use is not permitted by statutory regulation or exceeds the permitted use, you will need to obtain permission directly from the copyright holder. To view a copy of this licence, visit http://creativecommons.org/licenses/by/4.0/.

\section{References}

1. Waddell G, Burton AK. Is work good for your health and wellbeing?. London: The Stationery Office; 2006.

2. Waddel G, Burton AK, Kendall NA. Vocational rehabilitationwhat works, for whom, and when?. London: The Stationery Office; 2008.

3. Hoefsmit N, Houkes I, Nijhuis FJ. Intervention characteristics that facilitate return to work after sickness absence: a systematic literature review. J Occup Rehabil. 2012;22(4):462-477.

4. Cullen K, Irvin E, Collie A, Clay F, Gensby U, Jennings P, et al. Effectiveness of workplace interventions in return-to-work for musculoskeletal, pain-related and mental health conditions: an update of the evidence and messages for practitioners. J Occup Rehabil. 2018;28(1):1-15.

5. Vogel N, Schandelmaier S, Zumbrunn T, Ebrahim S, de Boer WE, Busse JW, et al. Return-to-work coordination programmes for improving return to work in workers on sick leave. Cochrane Database Syst Rev. 2017;3:CD011618.

6. Aasdahl L, Pape K, Vasseljen O, Johnsen R, Gismervik S, Halsteinli $\mathrm{V}$, et al. Effect of inpatient multicomponent occupational rehabilitation versus less comprehensive outpatient rehabilitation on sickness absence in persons with musculoskeletal- or mental health disorders: a randomized clinical trial. J Occup Rehabil. 2018;28(1):170-179.

7. Foster NE, Hill JC, Hay EM. Subgrouping patients with low back pain in primary care: are we getting any better at it? Man Ther. 2011;16(1):3-8.

8. Croft P, Altman DG, Deeks JJ, Dunn KM, Hay AD, Hemingway $\mathrm{H}$, et al. The science of clinical practice: disease diagnosis or patient prognosis? Evidence about "what is likely to happen" should shape clinical practice. BMC Med. 2015;13(1):20.

9. Vickers AJ, Basch E, Kattan MW. Against diagnosis. Ann Intern Med. 2008;149(3):200-203.

10. Norwegian Labour and Welfare Administration (NAV). Registered medically certified sick leave by diagnosis and place of residence, quarterly. Norwegian Labour and Welfare Administration. 2020. https://www.nav.no/no/nav-og-samfunn/statistikk/sykefravar-stati stikk/sykefravar. Accessed 30 Apr 2020.

11. Vos T, Allen C, Arora M, Barber RM, Bhutta ZA, Brown A, et al. Global, regional, and national incidence, prevalence, and years lived with disability for 310 diseases and injuries, 1990-2015: a systematic analysis for the Global Burden of Disease Study 2015. Lancet. 2016;388(10053):1545-1602.

12. Barnett K, Mercer SW, Norbury M, Watt G, Wyke S, Guthrie B. Epidemiology of multimorbidity and implications for health care, research, and medical education: a cross-sectional study. Lancet. 2012;380(9836):37-43.

13. Gragnano A, Negrini A, Miglioretti M, Corbière M. Common psychosocial factors predicting return to work after common mental disorders, cardiovascular diseases, and cancers: a review of reviews supporting a cross-disease approach. J Occup Rehabil. 2018;28(2):215-231.

14. Lloyd C, Waghorn G, McHugh C. Musculoskeletal disorders and comorbid depression: implications for practice. Aust Occup Ther J. 2008;55(1):23-29.

15. Black O, Keegel T, Sim MR, Collie A, Smith P. The effect of self-efficacy on return-to-work outcomes for workers with psychological or upper-body musculoskeletal injuries: a review of the literature. J Occup Rehabil. 2018;28(1):16-27.

16. Steenstra IA, Munhall C, Irvin E, Oranye N, Passmore S, Van Eerd D, et al. Systematic review of prognostic factors for return to work in workers with sub acute and chronic low back pain. J Occup Rehabil. 2017;27(3):369-381. 
17. Koopmans PC, Bültmann U, Roelen CAM, Hoedeman R, van der Klink JJL, Groothoff W. Recurrence of sickness absence due to common mental disorders. Int Arch Occup Environ Health. 2011;84(2):193-201.

18. Lötters F, Hogg-Johnson S, Burdorf A. Health status, its perceptions, and effect on return to work and recurrent sick leave. Spine. 2005;30(9):1086-1092.

19. Bouter LM, Pennick V, Bombardier C, Editorial Board of the Back Review Group. Cochrane back review group. Spine. 2003;28(12):1215-1218.

20. Westman AE, Boersma K, Leppert J, Linton SJ. Fear-avoidance beliefs, catastrophizing, and distress: a longitudinal subgroup analysis on patients with musculoskeletal pain. Clin J Pain. 2011;27(7):567-577.

21. Hirsch O, Strauch K, Held H, Redaelli M, Chenot J-F, Leonhardt $\mathrm{C}$, et al. Low back pain patient subgroups in primary care: pain characteristics, psychosocial determinants, and health care utilization. Clin J Pain. 2014;30(12):1023-1032.

22. Meisingset I, Vasseljen O, Vøllestad NK, et al. Novel approach towards musculoskeletal phenotypes. Eur J Pain. 2020;24(5):921-932.

23. Gross DP, Armijo-Olivo S, Shaw WS, Williams-Whitt K, Shaw NT, Hartvigsen J, Qin Z, Ha C, Woodhouse LJ, Steenstra IA. Clinical decision support tools for selecting interventions for patients with disabling musculoskeletal disorders: a scoping review. J Occup Rehab. 2016;26(3):286-318.

24. Hill JC, Whitehurst DG, Lewis M, Bryan S, Dunn KM, Foster $\mathrm{NE}$, et al. Comparison of stratified primary care management for low back pain with current best practice (STarT Back): a randomised controlled trial. Lancet. 2011;378(9802):1560-1571.

25. Louwerse I, van Rijssen HJ, Huysmans MA, van der Beek AJ, Anema JR. Predicting long-term sickness absence and identifying subgroups among individuals without an employment contract. J Occup Rehabil. 2020. https://doi.org/10.1007/s 1092 6-020-09874-2.

26. Foster NE, Hill JC, O'Sullivan P, Hancock M. Stratified models of care. Best Pract Res Clin Rheumatol. 2013;27(5):649-661.

27. Aasdahl L, Foldal VS, Standal MI, Hagen R, Johnsen R, Solbjor $\mathrm{M}$, et al. Motivational interviewing in long-term sickness absence: study protocol of a randomized controlled trial followed by qualitative and economic studies. BMC Public Health. 2018;18(1):756.

28. Folketrygdloven. National Insurance Act. Chapter 8. Sickness benefits. 1997. https://lovdata.no/nav/folketrygdloven/kap8/. Accessed 30 Apr 2020.

29. de Wit M, Wind H, Hulshof CTJ, Frings-Dresen MHW. Personrelated factors associated with work participation in employees with health problems: a systematic review. Int Arch Occup Environ Health. 2018;91(5):497-512.

30. Vargas-Prada S, Demou E, Lalloo D, Avila-Palencia I, Sanati KA, Sampere M, et al. Effectiveness of very early workplace interventions to reduce sickness absence: a systematic review of the literature and meta-analysis. Scand J Work Environ Health. 2016;42(4):261-272.

31. van Vilsteren M, van Oostrom SH, de Vet HCW, Franche R-L, Boot CRL, Anema JR. Workplace interventions to prevent work disability in workers on sick leave. Cochrane Database Syst Rev. 2015(10):CD006955.

32. Cancelliere C, Donovan J, Stochkendahl MJ, Biscardi M, Ammendolia C, Myburgh C, et al. Factors affecting return to work after injury or illness: best evidence synthesis of systematic reviews. Chiropr Man Therap. 2016;24(32):1-23.

33. Spitzer RL, Kroenke K, Williams JB, Lowe B. A brief measure for assessing generalized anxiety disorder: the GAD-7. Arch Intern Med. 2006;166(10):1092-1097.
34. Kroenke K, Spitzer RL, Williams JB. The PHQ-9: validity of a brief depression severity measure. J Gen Intern Med. 2001;16(9):606-613.

35. Kroenke K, Wu J, Yu Z, Bair MJ, Kean J, Stump T, et al. Patient health questionnaire anxiety and depression scale: initial validation in three clinical trials. Psychosom Med. 2016;78(6):716-727.

36. Cleeland CS, Ryan KM. Pain assessment: global use of the Brief Pain Inventory. Ann Acad Med Singap. 1994;23(2):129-138.

37. Klepstad P, Loge JH, Borchgrevink PC, Mendoza TR, Cleeland $\mathrm{CS}$, Kaasa S. The Norwegian brief pain inventory questionnaire: translation and validation in cancer pain patients. J Pain Symptom Manage. 2002;24(5):517-525.

38. Herdman M, Gudex C, Lloyd A, Janssen M, Kind P, Parkin $\mathrm{D}$, et al. Development and preliminary testing of the new five-level version of EQ-5D (EQ-5D-5L). Qual Life Res. 2011;20(10):1727-1736.

39. Tuomi K, Ilmarinen J, Eskelinen L, Jarvinen E, Toikkanen J, Klockars M. Prevalence and incidence rates of diseases and work ability in different work categories of municipal occupations. Scand J Work Environ Health. 1991;1:67-74.

40. Kinnunen U, Nätti J. Work ability score and future work ability as predictors of register-based disability pension and long-term sickness absence: a three-year follow-up study. Scand J Public Health. 2018;46(3):321-330.

41. Ahlstrom L, Grimby-Ekman A, Hagberg M, Dellve L. The work ability index and single-item question: associations with sick leave, symptoms, and health-a prospective study of women on long-term sick leave. Scand J Work Environ Health. 2010;36(5):404-412.

42. Lagerveld SE, Blonk RWB, Brenninkmeijer V, Schaufeli WB. Return to work among employees with mental health problems: development and validation of a self-efficacy questionnaire. Work Stress. 2010;24(4):359-375.

43. Folketrygdloven. National Insurance Act. https://lovdata.no/ dokument/NL/lov/1997-02-28-19. 1997. Accessed 30 Apr 2020.

44. World Organization of Family Doctors. ICPC-2. International Classification of Primary Care. Oxford: Oxford University Press; 1998.

45. Kongsted A, Nielsen AM. Latent class analysis in health research. J Physiother. 2017;63(1):55-58.

46. Magidson J, Vermunt J. Latent class models for clustering: a comparison with K-means. Can J Market Res. 2002;20(1):36-43.

47. Stahl D, Sallis H. Model-based cluster analysis. Wiley Interdiscip Rev Comput Stat. 2012;4(4):341-358.

48. Sclove SL. Application of model-selection criteria to some problems in multivariate analysis. Psychometrika. 1987;52(3):333-343.

49. Swanson SA, Lindenberg K, Bauer S, Crosby RD. A Monte Carlo investigation of factors influencing latent class analysis: an application to eating disorder research. Int J Eat Disord. 2012;45(5):677-684.

50. Nagin D. Group-based modeling of development. Cambridge: Harvard University Press; 2005.

51. Masyn KE. Latent class analysis and finite mixture modeling. In: Little TD, editor. The Oxford handbook of quantitative methods: Statistical analysis, vol 2. Oxford library of psychology. New York: Oxford University Press; 2013. p. 551-611.

52. Asparouhov T, Muthén B. Residual associations in latent class and latent transition analysis. Struct Equ Model. 2015;22(2):169-177.

53. Serlin RC, Mendoza TR, Nakamura Y, Edwards KR, Cleeland CS. When is cancer pain mild, moderate or severe? Grading pain severity by its interference with function. Pain. 1995;61(2):277-284. 
54. Fritz JM. Clinical prediction rules in physical therapy: coming of age? J Orthop Sports Phys Ther. 2009;39(3):159-161.

55. de Luca K, Parkinson L, Downie A, Blyth F, Byles J. Three subgroups of pain profiles identified in 227 women with arthritis: a latent class analysis. Clin Rheumatol. 2017;36(3):625-634.

56. Lee YC, Frits ML, Iannaccone CK, Weinblatt ME, Shadick NA, Williams DA, et al. Subgrouping of patients with rheumatoid arthritis based on pain, fatigue, inflammation, and psychosocial factors. Arthritis Rheumatol. 2014;66(8):2006-2014.

57. Virtanen M, Vahtera J, Head J, Dray-Spira R, Okuloff A, Tabak AG, et al. Work disability among employees with diabetes: latent class analysis of risk factors in three prospective cohort studies. PLoS ONE. 2015;10(11):e0143184.

58. Nielsen AM, Kent P, Hestbaek L, Vach W, Kongsted A. Identifying subgroups of patients using latent class analysis: should we use a single-stage or a two-stage approach? A methodological study using a cohort of patients with low back pain. BMC Musculoskelet Disord. 2017;18(1):57.

59. Larsen FB, Pedersen MH, Friis K, Glümer C, Lasgaard M. A latent class analysis of multimorbidity and the relationship to socio-demographic factors and health-related quality of life. A national population-based study of 162,283 Danish adults. PLoS ONE. 2017;12(1):e0169426.

60. Boersma K, Linton SJ. Screening to identify patients at risk: profiles of psychological risk factors for early intervention. Clin J Pain. 2005;21(1):38-72.

61. Reme SE, Shaw WS, Steenstra IA, Woiszwillo MJ, Pransky G, Linton SJ. Distressed, immobilized, or lacking employer support? A sub-classification of acute work-related low back pain. J Occup Rehabil. 2012;22(4):541-552.

62. Shaw WS, Pransky G, Patterson W, Linton SJ, Winters T. Patient clusters in acute, work-related back pain based on patterns of disability risk factors. J Occup Environ Med. 2007;49(2):185-193.

63. Halonen JI, Solovieva S, Virta LJ, Laaksonen M, Martimo KP, Hiljanen I, et al. Sustained return to work and work participation after a new legislation obligating employers to notify prolonged sickness absence. Scand J Public Health. 2018;46(19 suppl):65-73.

64. Sowden G, Hill JC, Morso L, Louw Q, Foster NE. Advancing practice for back pain through stratified care (STarT Back). Braz J Phys Ther. 2018;22(4):255-264.

65. Vermeulen SJ, Anema JR, Schellart AJ, Knol DL, van Mechelen W, van der Beek AJ. A participatory return-to-work intervention for temporary agency workers and unemployed workers sick-listed due to musculoskeletal disorders: results of a randomized controlled trial. J Occup Rehabil. 2011;21(3):313-324.
66. Nieuwenhuijsen K, Faber B, Verbeek JH, et al. Interventions to improve return to work in depressed people. Cochrane Database Syst Rev. 2014;(12):CD006237. https://doi.org/10.1002/14651 858.CD006237.pub3

67. Lagerveld SE, Blonk RW, Brenninkmeijer V, Wijngaards-de Meij L, Schaufeli WB. Work-focused treatment of common mental disorders and return to work: a comparative outcome study. J Occup Health Psychol. 2012;17(2):220.

68. van der Windt D, Hay E, Jellema P, Main C. Psychosocial interventions for low back pain in primary care: lessons learned from recent trials. Spine. 2008;33(1):81-89.

69. Bültmann U, Franche RL, Hogg-Johnson S, Côté P, Lee H, Severin C, Vidmar M, Carnide N. Health status, work limitations, and return-to-work trajectories in injured workers with musculoskeletal disorders. Qual Life Res. 2007;16(7):1167-1178.

70. Jørgensen CK, Fink P, Olesen F. Psychological distress among patients with musculoskeletal illness in general practice. Psychosomatics. 2000;41(4):321-329.

71. Steenstra IA, Ibrahim SA, Franche RL, Hogg-Johnson S, Shaw WS, Pransky GS. Validation of a risk factor-based intervention strategy model using data from the readiness for return to work cohort study. J Occup Rehabil. 2010;20(3):394-405.

72. Marin TJ, Van Eerd D, Irvin E, Couban R, Koes BW, Malmivaara A, et al. Multidisciplinary biopsychosocial rehabilitation for subacute low back pain. Cochrane Database Syst Rev. 2017;6:CD002193.

73. Shaw WS, Linton SJ, Pransky G. Reducing sickness absence from work due to low back pain: how well do intervention strategies match modifiable risk factors? J Occup Rehabil. 2006;16(4):591-605.

74. Flavel J. An analysis of the impact of health on occupation. Econ Rec. 2017;93:86-104.

75. Shaw WS, Reme SE, Pransky G, Woiszwillo MJ, Steenstra IA, Linton SJ. The pain recovery inventory of concerns and expectations: a psychosocial screening instrument to identify intervention needs among patients at elevated risk of back disability. J Occup Environ Med. 2013;55(8):885-894.

76. Hancock M, Herbert RD, Maher CG. A guide to interpretation of studies investigating subgroups of responders to physical therapy interventions. Phys Ther. 2009;89(7):698-704.

Publisher's Note Springer Nature remains neutral with regard to jurisdictional claims in published maps and institutional affiliations. 